\title{
RELATO ESPECULATIVO SOBRE DICHAS Y DESDICHAS DE LA UNIVERSIDAD
}

\author{
NOÉ JITRIK*
}

Universidade de Tandil, Argentina, 2007

\author{
II Encuentro Latinoamericano \\ "Universidad como objeto de investigación"
}

\footnotetext{
* Noé Jitrik nasceu em La Pampa (Argentina), em 1928. É professor na UBA, pesquisador, escritor e crítico literário. Autor das novelas "Limbo", "Citas de un día", "Mares del sur", "El evaluador" e "Long Beach". Tem uma extensa trajetória como ensaísta. Dirigiu a coleção "História crítica de la literatura argentina". É Doutor Honoris Causa da Universidad de Puebla. Recebeu, entre outros, dois Prêmios Konex (1994 y 2004) e o Prêmio Xavier Villaurrutia (1981).
} 
Keynote conference

\section{SPECULATIVE REPORT ABOUT THE SAID AND UNSAID IN HIGHER EDUCATION}

NOÉ JITRIK 


\title{
RELATO ESPECULATIVO SOBRE DICHAS Y DESDICHAS DE LA UNIVERSIDAD
}

\author{
NOÉ JITRIK* \\ (Leído en la apertura del V Encuentro Nacional y II Latinoamericano: \\ "La Universidad como objeto de investigación- Tandil 30 de agosto de 2007) \\ * Ficcionista e crítico argentino, docente na Universidad de Buenos Aires (UBA).
}

\section{DESPLAZAMIENTOS}

En la Antigüedad, el saber -había sabios en la Antigüedad, antiguos tal vez pero buenos- antes de ser escrito era oral: Sócrates, sin ir más lejos, hablaba y sus discípulos escuchaban, salvo Platón, que escribía lo que Sócrates -es una suposición- decía. Al viejo filósofo esa práctica de lo que ahora llamaríamos "extensión" le costó la vida y a los que lo precedieron la humillante designación de presocráticos. Un poco después, siempre dentro de lo que se llama muy en general la Antigüedad, el saber estaba recluido en los penosos libros escritos a mano en hojas de protopapel; los libros, a su vez, estaban recluidos en bibliotecas en parte porque valían y eran útiles, en parte también porque, prematuramente, eran corrosivos; tal vez por eso, en tristes jornadas, de cuando en cuando eran incendiadas, tal como ocurrió con la inolvidable de Alejandría. Se dice, y es probable que sea cierto, que eso demoró el desarrollo científico de la humanidad por varios siglos, pero qué importancia puede tener el tiempo para un pirómano.

Poco a poco, y acaso en virtud de esos cálidos antecedentes, el saber, entendido como producción de saber, se fue refugiando, en forma de libros, en lugares más secretos, aptos para preservarlo; me refiero a los monasterios aunque no es muy seguro que los monjes leyeran o, si no es de mi parte falta de información, los escribieran. Algunos lo hicieron, sin duda, como San Agustín y los llamados "padres de la iglesia" pero seguramente su irradiación no traspasaba los muros de los lugares santos. Umberto Eco, como seguramente todos lo recuerdan, describió esa situación libresca en El nombre de la rosa, mediante una ardua metáfora acerca del carácter mortífero de la palabra escrita, por más guardada que esté. 
Como presintiendo que la Edad Media estaba a punto de acabarse, muchos -algunos religiosos, otros mundanos- concibieron estructuras, llamadas "Universidades", destinadas no sólo a preservar el saber sino a producirlo y, además, a difundirlo, con una convicción: ese sistema podía ser muy útil para ayudar a la turbulenta y poco formada sociedad a entenderse, organizarse, salirse de las oscuridades que las entorpecían; filosofía, medicina, teología, gramática, podían salvar al género humano de los riesgos evidentes que corría, tropelías imperiales, pestes, utopías jerosolimitanas, misticismos suicidas, ignorancias absolutas, iniquidades sociales y muchas otras calamidades; de alguna manera, poco clara, esas instituciones democratizaban el saber pero eso, justamente, el hecho de que intentaran crear una red en la que la vida social se apoyara, les concedía un poder que en los primeros momentos no podía abrirse paso porque no podía competir con el poder de los imperios o monarquías y de la Iglesia, cada uno por separado o los dos juntos. Unos y otra habían entendido el potencial de las universidades y, por lo tanto, suponían que debían ponerse a su servicio.

En esa situación, al poder que otorgaba la producción, la reproducción y la difusión del saber, no le quedaba otra salida que volverse sobre sí mismo, consolidarlo se convirtió en programa, uno de cuyos puntos era la apasionante tarea de darle una orientación, dirigirlo, usufructuarlo, controlarlo: ser rector de una universidad se convirtió así en una meta aunque hacia afuera no pudiera competir con los otros poderes.

Tener poder adentro, en consecuencia, determinó un desplazamiento cuyos efectos todavía se sienten; dicho de otro modo, si el saber era el objeto de la creación de las universidades y éstas se convertían en el recinto del saber, muy pronto lo más importante era el recinto y no el saber guardado en él. La institución, cuyo núcleo significativo básico es la voluntad de perdurar, aunque su objeto esencial no sea ése, se concentra en su estructura y lo que la estructura pide lo cual, a su vez, genera multitud de asuntos que imitan las luchas por el poder, muchas veces por sí mismo, muchas veces, como habría dicho Nietzsche, por la voluntad de poder.

Dicho de otro modo, se genera en el interior de las universidades una vida propia y peculiar, con relaciones propias y peculiares, con modos y maneras distinguibles como propias y peculiares, con conflictos que no se parecen a ningún otro, con situaciones históricas altamente significativas; por ejemplo, la universidad como isla democrática, como refugio privilegiado de determinados privilegiados, como al servicio de la comunidad o indiferente a los pedidos que hace la sociedad, como lugar apetecible para instalarse y desde allí predicar la sabiduría o la competencia, como caverna misteriosa en la que 
algunos investigan y, en ocasiones, como premio a sus logros, emigran de sus países empujados por benévolos gobernantes que quieren ser generosos con los de otros países; también como poseedores de bibliotecas, que son como los restos de las viejas tradiciones, lo que las une con la Edad Media cuando las universidades empezaban a ver la luz y a emitir sus primeros gemidos. En fin, las universidades son micromundos en los que pasan muchas cosas, ésas, precisamente, que provocan curiosidad a quienes no están en ellas, casi morbo, objeto de indagación y de ficciones, lugar secreto lleno de recovecos, apto para la fantasía, también para enseñar y para investigar, aunque eso no parece encerrar ningún secreto interesante.

\section{FICCIÓN}

La vida interna de las universidades ha sido desde su comienzo un enigma para los de afuera, que podían imaginar que entre sus muros sucedían las cosas más descabelladas, y de intriga o problemática para los de adentro. La literatura ha sido bastante sensible a una u otra posición. Para la primera basta con recordar que de la Universidad de Wittemberg salió el mito de Fausto, que desde antes de Goethe atravesó luego toda la literatura universal, o bien la siniestra biblioteca de la Universidad de Arkham, en Providence, en la que un desaforado Lovecraft había instalado un ejemplar del Necronomicón, un libro demoníaco dotado de poderes y de explicaciones acerca del origen cetáceo de los habitantes de esa tormentosa región. Para la segunda, desde François Villon a Cervantes el estudiante deviene personaje, casi héroe de la picaresca, el estudiante es un muerto de hambre que inventa toda clase de argucias para comer, para violar criadas, para hacerse de dineros que de inmediato pierde en las juergas y, en fin, para dilapidar su tiempo en lugar de estudiar. No se sabe cuándo y cómo y qué estudian aunque se puede presumir que salieron del Trivium y el Cuadrivium o de las pedregosas cuestiones de la teología o de la Cábala pero sí se puede saber qué hacían para tolerar el frío inclemente de las aulas: a fuerza de patalear, en las clases de Fray Luis de León, en Salamanca, dejaron el piso de madera marcado, lleno de heridas, cómo habrán recibido las enseñanzas de ese angélico monje, al cual imaginamos diciendo constantemente, como un disco rayado, "como decíamos ayer", máxima expresión de continuidad académica.

Unos pillos los estudiantes, amantes de salidas nocturnas y autores de canciones procaces, como la famosa "los estudiantes navarros/chin pun/ comen pan y queso/ chorizo y jamón/ y el porrón", como si no hubieran tenido ninguna otra cosa que hacer. Haciéndose cargo de ese orden de relaciones surge la llamada 
"fiesta académica", esa hermosa obra de Brahms, cuyos versos exaltan la alegría de la juventud pero también la fugacidad de la existencia y que todavía algunos universitarios melancólicos festejan, en detrimento de la música de rock, poco o nada referida a la vida de la universidad aunque sí a los riesgos de la juventud.

La vida pícara, el desborde, el desafío, el lance secreto, los amores desaprensivos se eclipsan en el imaginario de la época de las luces, posterior al descubrimiento cartesiano que modifica, obviamente, el esquema intelectual de las universidades: la razón se abre paso penosamente y las penumbras medievales retroceden no sin resistencia, pero en el siglo XIX la melancolía romántica retoma el tema con toda la tristeza del caso: Espronceda escribe $E l$ estudiante de Salamanca, Chejov El estudiante, uno de sus mejores textos y hasta el caviloso Raskolnikov es un estudiante aunque no se sabe a qué Universidad asiste. Quienes, en cambio, no suscitan el interés de la literatura son los docentes, de poco interés para los escritores, sus vidas deben haber sido aburridas, como la del profesor Fausto antes de su pacto con el Diablo, o la del profesor Unrath, antes de caer en las redes de la encantadora y perversa "ángel azul", la divina Marlene Dietrich, pese a que en ese momento no tenía la estilizada figura que la hizo famosa.

Tarda un poco la literatura, en el siglo XX, en descubrir materia narrativa en las universidad; los estudiantes son otros, existen los que antiguamente se llamaban "bedeles" y últimamente no-docentes, y también, "last but not least", los reyes de la creación, los docentes, de modo que las relaciones entre todos ellos, además de integrar diversos comités y lugares de enfrentamientos salariales, ideológico políticos y espacios destinados a instalar adictos y a excluir desafectos, dan lugar a figuras interesantes para la literatura. En ese contexto, no puedo dejar de mencionar algunos textos importantes o, si no tanto, que al menos han llamado la atención de un público no universitario. Mi lista no será exhaustiva pero sí, espero, indicativa.

Empecemos con una obra de teatro que dio mucho que hablar en su momento, década del cincuenta: ¿Quién le teme a Virginia Wolf, de Edward Albee. Pone en escena la tradicional figura de un rector pero, y ahí está el punto, ese rector tiene una hija y la hija tiene relaciones con un profesor que el rector no estima. Me lo imagino al rector: muy parecido a los retratos de exrectores norteamericanos que perjudican las paredes de las salas de reunión; saco de tweed, pantalón de franela gris, corbata de moño sobre camisa celeste, bigote entrecano y consistente, $\mathrm{y}$ un aire de impenetrabilidad irreductible, tanto para los que golpean a su puerta como para la histeria de la hija a la cual la investidura del padre y su ciencia le importan poco, así como tampoco parece importarle 
el riesgo de incesto que planea como un pájaro por sobre las irritadas disputas.

De modo, inferimos, que en las Universidades deben existir conflictos que no pasan por los descubrimientos científicos pero también, en otros textos posteriores y en películas, los descubrimientos científicos pueden llegar a matar, además, desde luego, de provocar envidias, resentimientos, intrigas que son materia de narraciones más fantasiosas y divertidas, como es el caso de las novelas con que nos entretiene David Lodge.

Este autor fue muy celebrado porque se tomó en broma el universo mental de los universitarios, en particular especialistas en ciertos temas incombustibles, tipo Shakespeare, Adam Smith, Dickens y otros miembros de un grupo prometido a la eternidad. Lodge propone, es una hipótesis, tres razones para entender por qué los profesores van a los Congresos. 1. para hacerse escuchar por los 200 o 2000 asistentes, cada uno de los cuales intenta lo mismo; 2. para conseguir un empleo mejor que el que tienen; 3 . para ver si tienen suerte y logran internarse en alguna aventurita extramatrimonial. La ciencia, el saber, se convierte, desde luego, en un medio, de carne somos aunque seamos universitarios.

El ámbito universitario empieza a ser requerido por los buscadores de temas interesantes y proliferan las novelas que fantasean con crímenes interaulas, profesores malvados que manejan en secreto la vida de otros, investigaciones que de benéficas devienen letales, como lo muestra el célebre diálogo entre Niels Bohr y Werner Heisenberg en la exitosa Copenhague, crímenes nocturnos, tal, Crímenes imperceptibles, la inteligente narración de Guillermo Martínez, alumnos astutos que desbaratan oscuras maniobras de profesores taimados, abusos evaluativos, mi propia novela Evaluador, y laboratorios que durante la noche trafican con órganos humanos, compras de votos y ámbitos propicios, como se muestra en la novela Filo, de Sergio Holguín, para desarrollar actividades guerrilleras o bien, como es el caso de Amuleto, la novela del chileno Roberto Bolaño, habitantes clandestinos de los baños de las facultades, sin contar con la fauna de vendedores de baratijas y también, por qué no de drogas.

¿Se podría interpretar, de este interés por lo que ocurre en la Universidad, un propósito desviado, perverso, un intento no confesado de ridiculizar lo que significa la Universidad para la sociedad? Puede ser que sí, puede ser que eso no sea cierto y que lo que ocurre intramuros posea atractivos rasgos, matices tan ricos como los que ofrece cualquier ámbito social y, en consecuencia, tan susceptibles como cualquier otro, la aviación, la explotación, los viajes, la discriminación, el bajo fondo, la vida rumbosa de la aristocracia, la corrupción política, de hacer volar la imaginación y producir obras si no siempre trascendentales al menos, en muchos casos, entretenidas, incluso, a veces, críticas. 


\section{VIDA COTIDIANA}

En principio, quienes están en la Universidad parecen estar ahí desde siempre, son como el agua y el aire. Pero no es así, hay sistemas de reclutamiento diferentes para profesores, para estudiantes y para no docentes. El caso de estos últimos es el menos problemático: ocupan sus empleos como podrían hacerlo en cualquier otro lugar, aunque sus competencias pueden ser variadas. Los estudiantes ingresan, a veces a través de exámenes o de cursos preparatorios o por simple solicitud, depende de la estrategia de poblamiento que tengan las respectivas universidades. Lo más complicado se da en el ámbito profesoral. Se diría que hay tres vías de ingreso: el concurso, el contrato, el dedo. Sea como fuere, lo que cuenta son los méritos y, en el caso del concurso, actúan en esa instancia los llamados "pares", que han ingresado antes mediante el mismo procedimiento. Como los méritos son interpretables, se ha creado la instancia de la impugnación, a veces justificada, a veces sólo producto del rencor por no haberlo ganado. Sea como fuere los rencores que eso produce tienen formas muy diversas, desde el ataque hasta la hipocresía. El contrato es una forma de sortear los inconvenientes del concurso y su celebración depende ya no de los pares sino de las autoridades; a veces no hay más remedio, a veces es una forma de bloquear concursos y el acceso de docentes no estimados intelectual o ética o políticamente. Un problema en verdad. El dedo es interesante pero su acción se bifurca; en la primera dirección puede responder a una política de prestigio, la Universidad se honra en tener a equis en sus planteles; la segunda es el reino de la arbitrariedad. Cuando Spinoza recibió una carta de un Rector de una Universidad invitándolo a ingresar en ella la rechazó cortésmente porque dicho Rector le escribía por indicación del príncipe tal o el duque cual, admirador del filósofo pero no porque él personal y espontáneamente habría querido tomar esa iniciativa.

Lo más importante, lo permanente de la vida de la Universidad, es lo que ocurre en la dupla docentes y estudiantes, aunque en los últimos tiempos los antiguos bedeles, hoy no-docentes, se han incorporado a ese esquema y han alterado un tanto el carácter de bajo continuo que tiene aquella relación. En su forma primitiva, los docentes eran todopoderosos en materia de saber y de prestancia -en Francia los títulares de una cátedra eran llamados "patrón"- y los estudiantes les temían o los reverenciaban o se jactaban de haberlos seguido, eso era un título; las cosas han cambiado beneficiosamente en las últimas décadas de modo tal que ni los profesores son el "summum" del saber ni los estudiantes son sumisas páginas en blanco; al contrario, muchos de ellos, antes aún de haber concurrido a un libro enfrentan a los profesores, los refutan con convicción y, a 
partir de esa certeza, consiguen, a veces, dirigir la vida académica, el universo de la investigación y el destino de los antiguos dueños de la sabiduría.

Es obvio que la relación profesores-estudiantes es básica y esencial en la Universidad y, en principio, es bien vista y es objeto de pasión cuando no de expectativa de futuro: un buen estudiante puede ser estimado por un buen profesor y eso puede ser un buen dato para más adelante. Pero también tiene aspectos oscuros. Por ejemplo, eso que se ha designado como "acoso sexual", figura que hizo furor hace algunos años, en especial en las universidades norteamericanas y, como es previsible, pasó casi de inmediato a las nuestras. Como práctica, como actitud, debe haber existido siempre, no se puede negar las fáusticas tentaciones en personas de edad, por más que las posea el espíritu de seriedad de la ciencia, profesoras o profesores frente a jóvenes atractivos/atractivas y deslumbrados/deslumbradas. De ahí al manotón hay un solo paso, condenable, por cierto, porque implica un aprovechamiento poco delicado a partir de una posición de superioridad. Es más, el acoso venía ligado a lo académico, a saber si la o el joven oponía resistencia a la mano temblorosa del acosador su promoción corría grandes riesgos. Eso dio mucho que hablar y tuvo consecuencias prácticas: muchos profesores, acusados o sorprendidos en flagrante delito, debieron emigrar, otros dejaban las puertas de sus cubículos abiertas, por las dudas y, por último, muchos estudiantes encontraron divertido acusar sin razón a profesores antipáticos de modo de, simplemente, hacerles la vida imposible o bien obligarlos a modificar las notas que merecían o les parecían injustas. Sordos rumores de esta situación corrían por los pasillos de modo que muchos docentes, para terminar con ellos, recurrían al único medio idóneo, a la mejor defensa y, aplicándola, ordenaban de paso sus vidas; me refiero al casamiento entre profesores y alumnas, rara vez entre profesoras y alumnos.

Las relaciones interestudiantes tienen múltiples posibilidades. Ante todo, en las grandes ciudades latinoamericanas los estudiantes que vienen del interior del país se suelen alojar en determinadas zonas, en pensiones que les son recomendadas, a veces comparten departamentos, en otros lugares en residencias donde, de cuando en cuando se presentan conflictos debidos a prohibiciones variadas como, ejemplarmente, la de ir a visitar las habitaciones intersexos: como se recuerda, esa veda generó el movimiento conocido como "Mayo del 68 ", de mayúsculas consecuencias sociales y, acaso, de una vasta producción de hijos. Luego, en otro plano, se agrupan para estudiar y ahí nacen rivalidades de todo tipo, en especial, la vinculada con las citas: se han visto casos de estudiantes que han conseguido determinado libro y que, cuando le es pedido en préstamos, para citarlo a su vez, responden con todo tipo de argumentos para 
dejar huérfano al que no consiguió el libro salvador. En una etapa posterior, ya hechos al ámbito, se integran, al menos en América Latina, en grupos políticos, la razón de estar en la Universidad cambia radicalmente o, por lo menos, se matiza mucho; muchos descubren, en ese momento, una fuerte vocación pictórica y/o gráfica pero no figurativa sino letrística, siguiendo una importante corriente de la pintura contemporánea que pinta letras. Por fin, logran intervenir en el gobierno de la universidad pero todo eso acaba cuando se reciben y los espera el arduo camino de las decisiones: "lo" estudiante se va alejando y, en ocasiones, la actitud frente a la vida que va tomando forma es muy diferente de la que se tenía durante el período estudiantil.

\section{CONCLUSIÓN}

La Universidad es un potro difícil de domar; en sus recintos hay diversos hábitos, cierta cantidad de corrupción, se le ha metido dentro la política y los vendedores de baratijas y, sobrevolando esas notas, vocaciones de enseñar, vocaciones de aprender, espacio de crítica y termómetro de temas, relaciones que suelen establecerse para toda la vida. Fuera de sus recintos los prejuicios contra ella son numerosos y se expresan con la torpeza que suele ser propia de los prejuicios; además, es una presa codiciada y una película sensible, cada vez que tiene u problema brotan las ideas de abandonarla o de destruirla. Pero la Universidad continúa, no hay, hasta el presente, nada mejor. Defenderla, después de todo, no es una tarea vana. Espero que del relato que acabo de hacer se desprenda esta idea y que se lo vea coherente con lo que me he esforzado por mostrar. 